\title{
Selected physical properties of various diesel blends**
}

\author{
Zuzana Hlaváčová*, Monika Božiková, Peter Hlaváč, Tomáš Regrut, and Veronika Ardonová \\ Department of Physics, Slovak University of Agriculture in Nitra, Tr. A. Hlinku 2, SK-949 76 Nitra, Slovakia
}

Received August 16, 2017; accepted December 21, 2017

\begin{abstract}
A bstract. The quality determination of biofuels requires identifying the chemical and physical parameters. The key physical parameters are rheological, thermal and electrical properties. In our study, we investigated samples of diesel blends with rapeseed methyl esters content in the range from 3 to $100 \%$. In these, we measured basic thermophysical properties, including thermal conductivity and thermal diffusivity, using two different transient methods - the hot-wire method and the dynamic plane source. Every thermophysical parameter was measured 100 times using both methods for all samples. Dynamic viscosity was measured during the heating process under the temperature range $20-80^{\circ} \mathrm{C}$. A digital rotational viscometer (Brookfield DV 2T) was used for dynamic viscosity detection. Electrical conductivity was measured using digital conductivity meter (Model 1152) in a temperature range from -5 to $30^{\circ} \mathrm{C}$. The highest values of thermal parameters were reached in the diesel sample with the highest biofuel content. The dynamic viscosity of samples increased with higher concentration of bio-component rapeseed methyl esters. The electrical conductivity of blends also increased with rapeseed methyl esters content.
\end{abstract}

K e y w o rd s: diesel blends, rapeseed methyl ester, thermophysical, rheological and electrical properties

\section{INTRODUCTION}

The main advantages of biofuels are that these fuels are nontoxic, biodegradable and renewable, and hold the potential to reduce engine exhaust emissions. One of Europe's most important biofuels is fatty acid methyl esters (FAME), which is manufactured mainly as rapeseed methyl esters (RME). RME is added to regular diesel fuels in an amount of up to 7\% (Merkisz et al., 2016). The properties of rape-

*Corresponding author e-mail: zuzana.hlavacova@uniag.sk **This work was supported by the KEGA 017SPU-4/2017 project of Ministry of Education, Science, Research, and Sport of Slovakia and was co-funded by the European Community under project No 26220220180: Building the AgroBioTech Research Centre, 2013-2016. seeds and their products are described in Kovalyshyn et al. (2013), Novák (2011), Merkisz et al. (2016), and KachelJakubowska et al. (2017). The properties of various types of biofuels were investigated. Out of a number of vegetable oils, only a few are used commercially for biodiesel production. Due to various limitations of edible oil, nonedible oils are becoming a profitable choice. So far, a very low percentage of biodiesel has been used successfully in engines. There is continuing research on improving the biodiesel usage level.

Recently, it has been demonstrated that blended biodiesel from more than one feedstock provides better in-engine performance. For example, Liaquat et al. (2013), who studied the impact of coconut biodiesel blends on engine performance and emission characteristics, found that while the torque decreased and specific fuel consumption increased (compared to that of net diesel fuel), the emissions of $\mathrm{HC}$ and $\mathrm{CO}$ and sound levels were lower. Ruhul et al. (2016) and Abedin et al. (2016) also compared the impact of biodiesels made from non-edible feedstock on engine performance and emission characteristics. Rahman et al. (2017) investigated biodiesels made from microalgae and their effect on diesel engine performance.

To determine the quality of biofuels, it is necessary to identify the basic chemical and physical parameters of the feedstock. The key physical parameters are rheological, thermal and electrical properties, although other parameters could also be suggested. The methodology and results of direct thermal properties measurements performed on biofuels are presented by Machado et al. (2012). Yamane et al. (2001), Boshui et al. (2010), and Pelegrini et al. (2017) presented general oil, bio-oil, fuel and biofuel characteristics

(C) 2018 Institute of Agrophysics, Polish Academy of Sciences 
and their influence on thermal and rheological properties. Selected mechanical properties of pellets and biofuels were examined by Kubík and Kažimírová (2015), while rheological properties, such as kinematic and dynamic viscosity, were measured by Trávníček et al. (2013). Kosiba et al. (2016) investigated the rheological profiles and degradations of blends of new and used motor oils, while Kumbár et al. (2015) described the physical and mechanical properties of bioethanol and gasoline blends. Temperature dependencies of density and kinematic viscosity for petrol, bioethanol and their blends were measured by Kumbár and Dostál (2014), and the distribution of wear particles in oil samples and its influence on viscosity was evaluated by Kučera et al. (2016). M'Peko et al. (2013) found that the impedance spectroscopy is a sensible alternative and reliable analytical approach for distinguishing among different feedstock-related biodiesels, and for monitoring certain biofuel properties (such as viscosity and interrelated parameters) usually connected with fatty acid structural profiles in biodiesel fuels.

Measurements of complex permittivity and conductivity make it possible to efficiently survey the diverse steps of the industrial-scale production process, from raw material conditioning to final product quality control (El Khaled et al., 2016). Moreover, electrical measurements are nondestructive and require relatively small sample volumes. Electrical conductivity can also be used in measuring the content of some components, the impurities and other parameters in liquid fuels determination (Prieto et al., 2006; Žák and Marek, 2016).

This article presents certain selected physical properties of RME biodiesels in relation to those of conventional diesels. The aim of the research is to determine the changes of selected physical properties with increasing RME content in diesel.

\section{MATERIALS AND METHODS}

Dynamic methods of measurement, which are quicker than static methods, are in widespread use in modern physical research. Dynamic methods provide a quick way to obtain the characteristics of a material. This fact is very important for the practice. Herein, measured parameters are defined and the thermal, rheological and electrical measurement methods which were used for physical parameter detection are described. The measured diesel samples had different RME contents. The first sample was pure diesel and the subsequent measured samples had RME concentrations ranging from $3 \%$ to almost $80 \%$, respectively. All measured samples were stored in special bottles, and all samples were measured at various temperatures. Temperatures below $0^{\circ} \mathrm{C}$ were obtained by cooling the samples in dry ice. For higher temperatures, the samples were heated using an IKA RCT device Basic Safety Control.
Thermal conductivity $\lambda$, is the property of a material which relates to its ability to conduct heat. Thermal conductivity is defined as the quantity of heat transmitted through a unit surface to a unit temperature gradient in unit time. This thermophysical parameter depends on a number of factors, including material structure, pressure, chemical content, temperature, etc. When neighbouring molecules collide, energy is transferred from the more energetic to the less energetic molecules (Sahin and Sumnu, 2006). Thermal conductivity is mathematically defined by Fourier's law:

$$
\vec{q}=-\lambda\left(\frac{\partial T}{\partial x} \vec{i}+\frac{\partial T}{\partial y} \vec{j}+\frac{\partial T}{\partial z} \vec{k}\right)=-\lambda \operatorname{grad} T,
$$

where: $\vec{q}$ is the heat flux vector, while grad $T$ is the temperature gradient. The unit of thermal conductivity is $\mathrm{W}$ $\mathrm{m}^{-1} \mathrm{~K}^{-1}$. Thermal diffusivity $a$ characterizes the velocity of temperature equalization in materials during non-stationary processes. Numerically, it is equal to the unit volume temperature change induced by heat which is transferred in unit time, by unit surface of coat with unit thickness, in unit temperature difference on the facing side. The unit of thermal diffusivity is $\mathrm{m}^{2} \mathrm{~s}^{-1}$. Thermal diffusivity of homogeneous materials is expressed as:

$$
a=\frac{\lambda}{c \rho},
$$

where: the product $c \rho$ is volume specific heat, while $c$ is mass specific heat and $\rho$ is density of the material. Effusivity (e) of the sample is defined by Eq. (3):

$$
e=\frac{\lambda}{\sqrt{a}}=\sqrt{\rho c \lambda} .
$$

The thermal parameters of the tested diesel blends were measured using two transient methods: hot wire (HW) and dynamic plane source (DPS), so as to compare the quality of results. ISOMET 2104 (Applied Precision Ltd.) with needle and surface probes was used for all measurements. ISOMET 2104 is a portable measuring instrument used for the direct measurement of thermophysical properties of a wide range of materials. In the literature (Sahin and Sumnu, 2006), the HW method is preferred, although with the appropriate arrangement of experimental apparatus, DPS method can also be used. The HW method is a transient dynamic technique based on the measurement of the temperature rise of a linear heat source (hot wire) embedded in the tested material (Assael et al., 2008; Kadjo et al., 2008). For an infinitely long metallic wire (length/ radius ratio $>>200$ ) heated at the time span $t>0$, with a constant heat flux per length unit $q$ and immersed in an infinite homogeneous medium, thermal conductivity and diffusivity: $\lambda$ and $a$, and with uniform initial temperature, the temperature rise $\Delta T(t)$ of the wire is given by Eq. (4) (Wechsler, 1992): 


$$
\Delta T(t)=\frac{q}{4 \pi \lambda} \ln \frac{4 F_{0}}{C},
$$

with: $C=e^{\gamma}=1.781$, where $\gamma$ is the Euler's constant $(\gamma=$ 0.5772 ) and $F_{0}$ is the Fourier number defined by:

$$
F_{0}=\frac{a t}{r_{0}^{2}} .
$$

Equation (4) is the analytical solution of an ideal thermal conductive model valid for $F_{0} \gg 1$ and without convective transfers wherein $r_{0}$ is the distance from the hot wire (Tavman, 1996). From this ideal model and with known $q$ values, sample thermal conductivity can be calculated by:

$$
\lambda=\frac{q}{4 \pi}\left(\frac{d T}{d(\ln t)}\right)^{-1},
$$

where: $d T / d(\ln t)$ is a numerical constant deduced from experimental data for $t$ values which satisfy the condition $F_{0} \gg>1$. For practical applications of the HW method, wire and material sample dimensions, among other ideal model hypothesis, are finite and the deviations from the ideal model have then to be evaluated. In fact, the $e(t)$ answer to the wire heating $\Delta T(t)$ resultant of the Joule effect due to an electrical current $i$ is:

$$
R(t)=R_{0}\left(1+\beta_{0}\left(T(t)-T_{0}\right)\right),
$$

where: $R(t)$ is the instantaneous electrical resistance of the wire, $R_{0}$ is the resistance of the wire at the reference temperature $T_{0}$, and $\beta_{0}$ is the temperature coefficient of the wire at $22{ }^{\circ} \mathrm{C}$. Taking into account Eqs (6) and (7), the thermal conductivity $\lambda$ may be calculated as follows:

$$
\lambda=\frac{q R_{0} \beta_{0} i}{4 \pi}\left(\frac{d e(t)}{d(\ln t)}\right)^{-1},
$$

where: $d e(t) / d(\ln t)$ is a numerical constant deduced from the experimental data and from the linear part of the $e(t)=$ $f(\ln (t))$ curve.

The DPS method is based on using an ideal plane sensor (PS). Herein, the plane sensor acts both as heat source and temperature detector, and the plane source method is arranged for a one-dimensional heat flow into a finite sample. The theory considers ideal experimental conditions: ideal heater (negligible thickness and mass), perfect thermal contact between PS and the sample, zero thermal resistance between the sample and the material surrounding the sample, as well as zero heat losses from the lateral surfaces of the sample (Karawacki et al., 1992). If $q$ is the total output of power per unit area dissipated by the heater, then the temperature increase as function of time is given by:

$$
\Delta T(x, t)=2 \frac{q \sqrt{a t}}{\lambda} \operatorname{ierf}\left(\frac{x}{2 \sqrt{a t}}\right),
$$

ierf is the error function (Beck and Arnold, 2003). The principle of this method involves fitting of the theoretical temperature function given by theoretical equation over the experimental points. In situations of the best fit, both parameters $\lambda$ and $a$ can be determined. The method of fitting based on least-squares procedure was described in detail (Malinarič, 2004).

Rheological data are important in product quality evaluation, engineering calculations and process design. It is necessary to know or understand the flow behaviour in determining the size of the pump and pipe needed, as well as for energy requirements. Rheological models built upon experimental measurements can also be useful in the design of material engineering processes in connection with energy and mass balances, as the effect of processing on rheological properties must be known for process control (Sahin and Sumnu, 2006). From the rheological parameters, it is also possible to measure the dynamic viscosity $\eta$, which is very important for liquids, and can be defined as the resistance of a fluid to flow. The unit of dynamic viscosity is Pa s. As viscous fluids tend to deform continuously under the effect of an applied stress, we can divide viscous fluids into two parts: Newtonian and non-Newtonian fluids, by applying Newton's law of viscosity:

$$
\tau=\eta \operatorname{grad} v,
$$

where: $\tau$ is shear stress and grad $v$ is the gradient of velocity (or shear rate). Fluids that follow Newton's law of viscosity are called Newtonian fluids. The slope of dependency between shear stress and shear rate, which is viscosity, is constant and independent of shear rate for this type of liquids.

Capillary flow, orifice type, falling ball and rotational viscometers are the most commonly used viscometers to measure viscosity of materials. In our work, the measurement of dynamic viscosity was performed by utilizing a Brookfield DV 2T digital viscometer. The principle of measuring using a rotational viscometer is based on dependency of sample resistance against the probe rotation. A spindle attached to the instrument with a vertical shaft is rotated in the fluid and the torque necessary to overcome the viscous resistance is measured. Different spindles are available in various sizes which may be rotated at different speeds. A suitable spindle and a rotational speed for a particular fluid are selected by trial and error. This viscometer directly provides the viscosity of Newtonian's fluids, because it is calibrated with Newtonian oils, and a range of calibration fluids is available for ascertaining the accuracy of the apparatus. It is possible to determine whether the fluid is time dependent or not by using this viscometer (Sahin and Sumnu, 2006). A probe labelled ULA0 was used in our measurements. The frequency of probe rotation was $120 \mathrm{~min}^{-1}$. 
Electrical properties are used in many areas of human activity. They are also important in sustainable biofuel production for minimizing the environmental impact through proper plant design and control of the washing process during production (Prieto et al., 2008). Electrical properties are the properties which characterize the transport of charge carriers in the material or propagation of electromagnetic waves in materials. The measured electrical properties include electric conductance, conductivity, electric resistance, resistivity, impedance, admittance, permittivity, relative permittivity, complex permittivity, dielectric loss angle, loss tangent and Maxwell's relaxation constant. For fuel and biofuel, researchers mainly investigate conductivity. Conductance $-G(\mathrm{~S})$ is the ability of the material to conduct the electric current. Herein, ions are charge carriers related to the ionic conductance, which most frequently occurs in liquids. Conductivity $-s\left(\mathrm{~S} \mathrm{~m}^{-1}\right)$ is the conductance of material related to its proportions. In our work, the conductivity of biodiesel blends was measured by using a Digital Conductivity Meter Model 1152 (Emcee Electronics, Inc.) ASTM Standard Test Method D 2624, with (1-2000) $\mathrm{pS} \mathrm{m}^{-1}$ measurement range, $2 \%$, and \pm $1 \mathrm{pS} \mathrm{m}^{-1}$ measurement accuracy. The samples were heated using a Magnetic stirrer with heating IKA RCT Basic Safety Control. The conductivity was measured in the temperature range from -5 to $30^{\circ} \mathrm{C}$.

\section{RESULTS AND DISCUSSION}

All results were obtained by undertaking laboratory measurements at a temperature of $22^{\circ} \mathrm{C}$. All samples were first stabilised $24 \mathrm{~h}$ before measurement. For the thermophysical data, reliability protection was achieved by undertaking a series of one hundred measurements for every sample of diesel with RME and every thermal parameter was measured by both HW and DPS methods. Table 1 presents the average values. Standard deviation and relative standard deviation in \% was calculated for every series of measurements.

The measured values of thermal parameters showed that increasing the concentration of bio-components in the fuel had significant influence on all investigated physical parameters. The lowest values of thermal parameters were detected for samples of pure diesel that were measured using the HW method. The thermal conductivity of pure diesel was $(0.1472 \pm 0.0002) \mathrm{W} \mathrm{m}^{-1} \mathrm{~K}^{-1}$ and the thermal diffusivity $(A)$ was $(0.7897 \pm 0.0011) 10^{-7} \mathrm{~m}^{2} \mathrm{~s}^{-1}$. From basic thermal parameters and density of samples, the value of volume specific heat $c \rho=(0.1864 \pm=0.0004) 10^{7} \mathrm{~J} \mathrm{~m}^{-3}$ $\mathrm{K}^{-1}$ and effusivity $e=(5.2381 \pm 0.0099) 10^{-5} \mathrm{~W} \mathrm{~m}^{-2} \mathrm{~K}^{-1} \mathrm{~s}^{-0.5}$ were calculated. Diesel with the addition of $20 \% \mathrm{RME}$ had the highest values of thermal parameters as measured by the DPS method. Herein, thermal conductivity was $(0.1725$ $\pm 0.0009) \mathrm{W} \mathrm{m}^{-1} \mathrm{~K}^{-1}$, and the thermal diffusivity of the

Table 1. Results of thermal parameter measurements using the HW and DPS methods for samples of diesel with different RME content

\begin{tabular}{ccccc}
\hline $\begin{array}{c}\text { RME content } \\
(\%)\end{array}$ & $\begin{array}{c}\lambda \\
\left(\mathrm{W} \mathrm{m}^{-1} \mathrm{~K}^{-1}\right)\end{array}$ & $\begin{array}{c}A \\
\left(10^{-7} \mathrm{~m}^{2} \mathrm{~s}^{-1}\right)\end{array}$ & $\begin{array}{c}c \rho \\
\left(10^{7} \mathrm{~J} \mathrm{~m}^{-3} \mathrm{~K}^{-1}\right)\end{array}$ & $\begin{array}{c}e \\
\left(10^{-5} \mathrm{~W} \mathrm{~m}^{-2} \mathrm{~K}^{-1} \mathrm{~s}^{-0.5}\right)\end{array}$ \\
\hline 0 & & HW method & \\
3 & $0.1472 \pm 0.0002$ & $0.7897 \pm 0.0011$ & $0.1864 \pm 0.0004$ & $5.2381 \pm 0.0099$ \\
7 & $0.1526 \pm 0.0004$ & $0.8034 \pm 0.0005$ & $0.1899 \pm 0.0005$ & $5.3832 \pm 0.0140$ \\
10 & $0.1581 \pm 0.0004$ & $0.8153 \pm 0.0008$ & $0.1939 \pm 0.0004$ & $5.5367 \pm 0.0110$ \\
15 & $0.1620 \pm 0.0003$ & $0.8199 \pm 0.0003$ & $0.1977 \pm 0.0004$ & $5.6593 \pm 0.0120$ \\
20 & $0.1662 \pm 0.0004$ & $0.8217 \pm 0.0004$ & $0.2022 \pm 0.0005$ & $5.7970 \pm 0.0140$ \\
& $0.1716 \pm 0.0004$ & $0.8278 \pm 0.0005$ & $0.2073 \pm 0.0005$ & $5.9643 \pm 0.0140$ \\
3 & & $\mathrm{DPS}$ method & & \\
7 & $0.1480 \pm 0.0005$ & $0.7902 \pm 0.0039$ & $0.1873 \pm 0.0011$ & $5.2650 \pm 0.0122$ \\
10 & $0.1530 \pm 0.0007$ & $0.8045 \pm 0.0016$ & $0.1902 \pm 0.0009$ & $5.3945 \pm 0.0360$ \\
15 & $0.1593 \pm 0.0006$ & $0.8170 \pm 0.0011$ & $0.1950 \pm 0.0010$ & $5.5735 \pm 0.0280$ \\
20 & $0.1650 \pm 0.0004$ & $0.8208 \pm 0.0005$ & $0.2010 \pm 0.0008$ & $5.7589 \pm 0.0340$ \\
& $0.1681 \pm 0.0007$ & $0.8226 \pm 0.0008$ & $0.2044 \pm 0.0008$ & $5.8617 \pm 0.0440$ \\
\hline
\end{tabular}


sample was $(0.8297 \pm 0.0007) 10^{-7} \mathrm{~m}^{2} \mathrm{~s}^{-1}$. The presented results are in good agreement with values seen in literature (Machado et al., 2012). The obtained thermal effusivity of the sample was $e=(5.9886 \pm 0.0510) 10^{-5} \mathrm{~W} \mathrm{~m}^{-2} \mathrm{~K}^{-1} \mathrm{~s}^{-0.5}$ and the volume specific heat was $c \rho=(0.2079 \pm 0.0006)$ $10^{7} \mathrm{~J} \mathrm{~m}^{-3} \mathrm{~K}^{-1}$. Of note, values of volume specific heat and effusivity for diesel samples with different RME content were not compared with the results in the literature because no prior data was found.

One of the main aims of performing thermal parameter measurements was to compare the effectiveness of the two different types of thermophysical parameter measurement methods. From the results presented in Table 1 it is evident, that the relative standard deviation of thermal parameter measurements for the HW method was from \pm 0.03 to $\pm 0.27 \%$, and the same relative deviations for DPS method were in the range from \pm 0.06 to $\pm 0.86 \%$. The results of the comparison of the two measurement methods confirmed that it is more appropriate to use the HW rather than the DPS method for the tested materials. This fact was presented in literature (Roder, 1981), but the detected minimal differences between basic thermal parameters values showed that, with the appropriate arrangement of the measuring apparatus, both thermophysical measurement methods can be used.

In this study, dynamic viscosity (considered a basic rheological parameter) was also determined. All samples were measured through employing a heating process in the temperature range of $20-80^{\circ} \mathrm{C}$. Every point in graphical dependencies in Fig. 1 was obtained as average from ten measured values for each sample of diesel with different RME content.

The data in Fig. 1 show that the dynamic viscosity of the diesel blends decreases with the increase of temperature. The progress can be described by using the decreasing exponential function Eq. (11):

$$
\eta=\eta_{0} e^{-A \frac{t}{t_{0}}}
$$

where: $\eta_{0}$ is the reference value of dynamic viscosity, $A$ is a constant, $t_{0}=1^{\circ} \mathrm{C}$. Coefficients of regression equation Eq. (11) and coefficients of determination are shown in Table 2. On the basis of the presented results, it is clear that the coefficients of determination are in range of 0.9932 -0.9983 .

The viscosity of liquids usually decreases with increasing temperature, and the difference in the effect of temperature on the viscosity of fluids is related to the difference in their molecular structure (Machado et al., 2012). The temperature effect on dynamic viscosity can be described by an Arrhenius type equation:

$$
\eta=\eta_{0} e^{-\frac{E_{A}}{\mathrm{RT}}}
$$

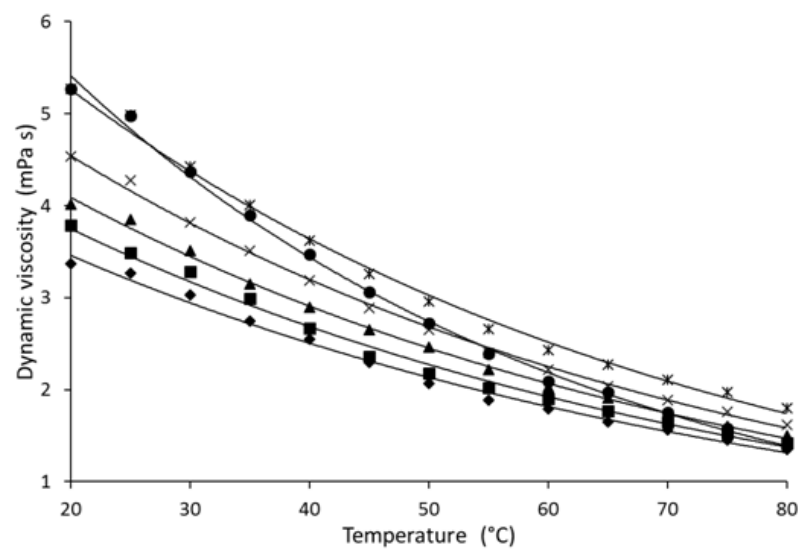

Fig. 1. Temperature dependencies of dynamic viscosity for samples of diesel with different RME content: $0 \%$ - •, 3\% - - , 7\% - $\boldsymbol{\Delta}$, $10 \%-\mathrm{x}, 15 \%$ - *, 20\% - • .

Table 2. Coefficients $\eta_{0}$ and $A$ of regression Eq. (11) and coefficient of determination $\mathrm{R}^{2}$ for relations of dynamic viscosity to the temperature

\begin{tabular}{cccc}
\hline $\begin{array}{c}\text { RME content } \\
(\%)\end{array}$ & $\begin{array}{c}\eta_{0} \\
(\mathrm{mPa} \mathrm{s})\end{array}$ & $A$ & $\mathrm{R}^{2}$ \\
\hline 0 & 4.7715 & 0.016 & 0.9944 \\
3 & 5.2328 & 0.017 & 0.9932 \\
7 & 5.7492 & 0.017 & 0.9983 \\
10 & 6.4549 & 0.018 & 0.998 \\
15 & 7.6053 & 0.018 & 0.9952 \\
20 & 8.5145 & 0.023 & 0.9978 \\
\hline
\end{tabular}

where: $\eta_{0}$ is the reference value of dynamic viscosity, $E_{A}$ is activation energy, $\mathrm{R}$ is a gas constant and $\mathrm{T}$ is absolute temperature (Figura and Teixeira, 2007). Eq. (11) for temperature dependence of dynamic viscosity is in good accordance with the Arrhenius equation.

From Fig. 1, it can be seen that the dynamic viscosity of diesel with an RME component is higher than that of pure diesel. In general, the dynamic viscosity of diesel increases with higher concentration of the bio component RME (Pelegrini et al., 2017). However, we detected a difference only for diesel sample with $20 \%$ RME content. The biodiesel blends presented Newtonian behaviour in this temperature range, and this notion is in good accordance with the literature e.g. for biodiesel from Sapindus saponaria L. (Pelegrini et al., 2017).

Empirical or proprietary blending equations are also common for fuel blends. The best known are the doublelogarithmic equation of Refutas and the cubic-root equation of Kendall and Monroe (Zhmud, 2014). The Refutas equation calculates the kinematic viscosity of the binary blend 
from viscosities and mass fractions of the components by introducing the so-called viscosity blending index. The dynamic viscosity of an ideal binary mixture consisting of the components with viscosities $\eta_{1}$ and $\eta_{2}$ obeys the Arrhenius mixing equation:

$$
\eta_{1,2}=x_{1} \ln \eta_{1}+x_{2} \ln \eta_{2}
$$

where: $x_{1}$ and $x_{2}$ are the mole fraction of the components in the mixture (Zhmud, 2014).

Electrical conductivity $(\sigma)$ of biodiesel blends was measured at various temperatures from -5 to $30^{\circ} \mathrm{C}$. In Fig. 2, the temperature dependency of conductivity for a blend with $65 \%$ of RME can be seen. Herein, the conductivity increases with increasing temperature, which is caused by dissociation of the molecules to ions. Biofuels with more ions have higher conductivity. A second factor is the increase of the velocity of ions. For all blends with various RME content, the conductivity increased with temperature. The present findings are in accordance with the results of Rocha and Simões-Moreira (2005), which state that the conductivity of hydrocarbon fuels and solvents are generally temperature dependent, primarily due to changes in the mobility of the conducting species related to fuel viscosity effects.

As a model describing these dependencies, we used the following exponential regression function:

$$
\sigma=\sigma_{0} e^{\mathrm{k} \frac{t}{t_{0}}}
$$

where: $\sigma_{0}$ is the reference value of conductivity, $\mathrm{k}-\mathrm{a}$ constant, while $t_{0}=1^{\circ} \mathrm{C}$. Equation (14) has a high coefficient of determination for all dependencies, e.g. for the curve on Fig. $2, \mathrm{R}^{2}=0.9587$. This model is also in good relation with Arrhenius equation for conductivity:

$$
\sigma=\sigma_{0} e^{\frac{E_{A}}{R T}} .
$$

Figure 3 shows the RME content dependency of conductivity at the temperature of $10^{\circ} \mathrm{C}$. However, we found that fuel conductivity is affected by the presence of biodiesel at all temperatures.

The cubic polynomial model can be used for describing the increase of function for all temperatures:

$$
\sigma=\mathrm{m} c^{3}-\mathrm{n} c^{2}+\mathrm{p} c-\mathrm{r} .
$$

In this, $c$ is the RME concentration, and $\mathrm{m}, \mathrm{n}, \mathrm{p}, \mathrm{r}$ are constants. The values of regression coefficients at a temperature of $10^{\circ} \mathrm{C}$ were: $\mathrm{m}=0.0224 \mathrm{pS} \mathrm{m}^{-1}, \mathrm{n}=2.7203 \mathrm{pS} \mathrm{m}^{-1}$, $\mathrm{p}=115.6 \mathrm{pS} \mathrm{m}^{-1}, \mathrm{r}=1377.6 \mathrm{pS} \mathrm{m}^{-1}$. This model has a high coefficient of determination: $\mathrm{R}^{2}=0.9928$. We saw that conductivity increases with increasing RME content. This is caused by the different chemical compositions of diesel and RME. The polynomial model Eq. (16) could be used for determining RME content in biodiesels. A similar method was recommended by Corach et al. (2017) by using rela-

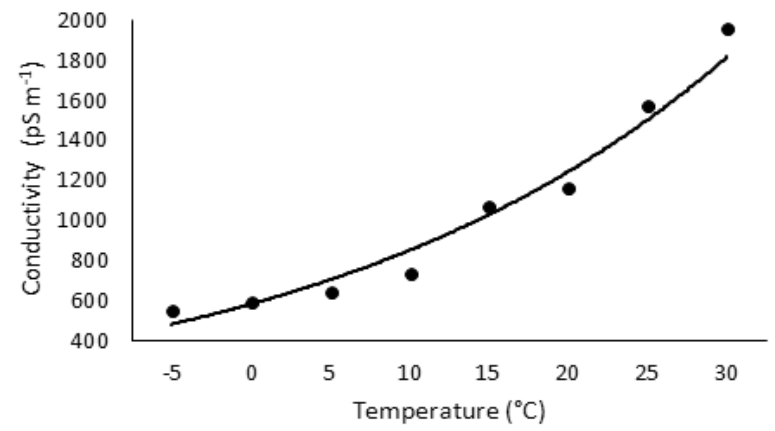

Fig. 2. Temperature dependency of conductivity of sample with $65 \%$ of RME.

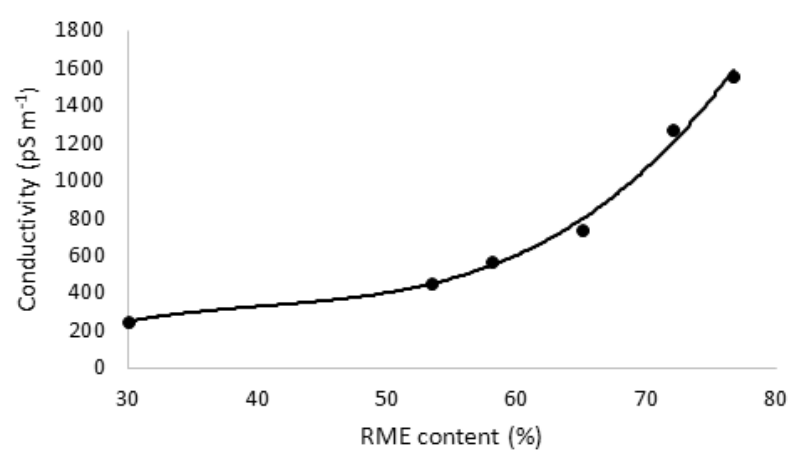

Fig. 3. Conductivity in comparison to RME content in diesel.

tive permittivity dependence on RME content. The electric impedance sensor for determining mass ratios in ethanol and regular gasoline blends was designed by Rocha and Simões-Moreira (2005).

\section{CONCLUSIONS}

1. The thermophysical properties of various diesel and rapeseed methyl esters blends were measured by two methods - hot wire and dynamic plane source.

2. A comparison of the results of the two measurement methods confirmed that for liquid materials, application of the hot wire method is more appropriate.

3. The dynamic viscosity of diesel blends decreases with increasing temperature. The progress can be described by utilizing the decreasing exponential function.

4. The results of our study can be used for dynamic viscosity of blend calculation according to the Arrhenius mixing equation.

5. For all blends with various rapeseed methyl esters content, the conductivity increases with increasing temperature. In modelling this, we used an exponential regression function.

6. The temperature dependencies of dynamic viscosity and conductivity are in good accordance with the Arrhenius equation.

7. Conductivity increases with increasing rapeseed methyl esters content in diesel blends. The cubic polynomial model can be used for describing the function for all 
temperatures. Moreover, the polynomial model Eq. (16) could be used for determining rapeseed methyl esters content in diesel.

Conflict of interest: The Authors do not declare conflict of interest.

\section{REFERENCES}

Abedin M.J., Kalam M.A., Masjuki H.H., Sabri M.F.M., Rahman S.M.A., Sanjid A., and Fattah I.M.R., 2016. Production of biodiesel from a non-edible source and study of its combustion, and emission characteristics: A comparative study with B5. Renewable Energy, 88, 20-29.

Assael M.J., Antoniadis K.D., and Wu J., 2008. New measurements of the thermal conductivity of PMMA, BK7, and Pyrex 7740 up to $450 \mathrm{~K}$. Int. J. Thermophysics, 29(4), 1257-1266.

Beck J.V. and Arnold K.J., 2003. Parameter estimation in engineering and science. John Wiley, New York, USA.

Boshui C., Yuqiu S., Jianhua F., Jiu W., and Jiang W., 2010. Low-temperature properties of biodiesel: rheological behaviour and crystallization morphology. China Petroleum Proc. Petrochemical Technol., 12, 29-33.

Corach J., Sorichetti P.A., and Romano S.D., 2017. Permittivity of diesel fossil fuel and blends with biodiesel in the full range from $0 \%$ to $100 \%$ : Application to biodiesel content estimation. Fuel, 188, 367-373.

El Khaled D., Novas N., Gázquez J.A., García R.M., and Manzano-Agugliaro F., 2016. Alcohols and alcohols mixtures as liquid biofuels: A review of dielectric properties. Renewable Sustainable Energy Reviews, 66, 556-571.

Figura L.O. and Teixeira A.A., 2007. Food Physics, Physical properties - measurement and applications. Springer, New York, USA.

Kachel-Jakubowska M., Matwijczuk A., and Gagoś M., 2017. Analysis of the physicochemical properties of post-manufacturing waste derived from production of methyl esters from rapeseed oil. Int. Agrophys., 31(2), 175-182.

Kadjo A., Garnier J.P., Maye J.P., and Martemianov S., 2008. A new transient two-wire method for measuring the thermal diffusivity of electrically conducting and highly corrosive liquids using small samples. Int. J. Thermophysics, 29(4), 1267-1277.

Karawacki E., Suleiman B.M., Ul-Hang I., and Nhi B.T., 1992. An extension to the dynamic plane source technique for measuring thermal conductivity, thermal diffusivity and specific heat of solids. Review of Scientific Instruments, 63, 4390-4397.

Kosiba J., Čorňák Š., Glos J., Jablonický J., Vozárová V., Petrović A., and Csilllag J., 2016. Monitoring oil degradation during operating test. Agronomy Res., 14(5), 1626-1634.

Kovalyshyn J., Shvets O.P., Grundas S., and Tys J., 2013. Use of the electro-separation method for improvement of the utility value of winter rapeseeds. Int. Agrophys., 27(4), 419-424.

Kubík L'. and Kažimírová V., 2015. Mechanical properties of pellets in compression. Res. Agr. Eng., 61(special iss.), S1-S8.

Kučera M., Aleš Z., Pavlů J., and Hnilicová M., 2016. Applying of automatic laser particle counter as technique to morpho- logy assessment and distribution of wear particles during lifetime of transmission oils. Key Engineering Materials, $669,417-425$.

Kumbár V. and Dostál P., 2014. Temperature dependence density and kinematic viscosity of petrol, bioethanol and their blends. Pak. J. Agri. Sci., 51(1), 175-179.

Kumbár V., Polcar A., and Votava J., 2015. Physical and mechanical properties of bioethanol and gasoline blends (in Czech). Listy cukrovarnické a řepařské, 131(3), 112-116.

Liaquat A.M., Masjuki H.H., Kalam M.A., Fattah I.M.R., Hazrat M.A., Varman M., Mofijur M., and Shahabuddin M., 2013. Effect of coconut biodiesel blended fuels on engine performance and emission characteristics. Procedia Eng., 56, 583-590.

Machado F.A.L., Zanelato E.B., Guimarães A.O., da Silva E.C., and Mansanares A.M., 2012. Thermal properties of biodiesel and their corresponding precursor vegetable oils obtained by photopyroelectric methodology. Int. J. Thermoph., 33(10), 1848-1851.

Malinarič S., 2004. Parameter estimation in dynamic plane source method. Measurement Sci. Technol., 15(4), 807-813.

Merkisz J., Fuć P., Lijewski P., and Kozak M., 2016. Rapeseed oil methyl esters (RME) as fuel for urban transport. In: Environmental Sciences 'Alternative Fuels, Technical and Environmental Conditions', (Ed. K. Biernat), 3.0 license CC BY 2016.

M'Peko J.C., Reis D.L.S., De Souza J.E., and Caires A.R.L., 2013. Evaluation of the dielectric properties of biodiesel fuels produced from different vegetable oil feedstocks through electrochemical impedance spectroscopy. Int. J. Hydrogen Energy, 38, 9355-9359.

Novák J., 2011. Electrical Properties of Colza Seeds. Acta technologica agriculturae, 14(1), 11-14.

Pelegrini B.L., Sudati E.A., Ré F., Moreira A.L., Ferreira I.C.P., Sampaio A.R., Kimura N.M., and de Souza Lima M.M., 2017. Thermal and rheological properties of soapberry Sapindus saponaria L. (Sapindaceae) oil biodiesel and its blends with petrodiesel. Fuel, 199, 627-640.

Prieto L.E.G., Sorichetti P.A., and Romano S.D., 2008. Electric properties of biodiesel in the range from $20 \mathrm{~Hz}$ to $20 \mathrm{MHz}$. Comparison with diesel fossil fuel. Int. J. Hydrogen Energy, 33, 3531-3537.

Rahman M.A., Aziz M.A., Ruhul A.M., and Rashid M.M., 2017. Biodiesel production process optimization from Spirulina maxima microalgae and performance investigation in a diesel engine. J. Mechanical Sci. Technol., 31(6), 3025-3033.

Rocha M.S. and Simões-Moreira J.R., 2005. A simple impedance method for determining ethanol and regular gasoline mixtures mass contents. Fuel, 84, 447-452.

Roder H.M., 1981. A transient hot wire thermal conductivity apparatus for fluids. J. Res. Natl. Bur. Stand., 86, 457-480.

Ruhul A.M., Masjuki H.H., Kalam M.A., Shahir S.A., Reham S.S., and Shancita I., 2016. Biodiesel production, properties and emissions test characteristics of nonedible fuels in diesel engine. J. Scientific Res. Development, 3(1), 101-106.

Sahin S. and Sumnu S.G., 2006. Physical properties of foods. Springer, New York, USA.

Tavman I.H., 1996. Effective thermal conductivity of granular porous materials. Int. Communications in Heat and Mass Transfer, 23(2), 169-176. 
Trávníček P., Valach M., Hlaváčová Z., Mareček J., Vítěz T., and Junga P., 2013. Selected physical properties of liquid biofuels. Res. Agr. Eng., 59(4), 121-127.

Wechsler A.E., 1992. The probe method for measurement of thermal conductivity in compendium of thermophysical property measurement methods. Recommended measurement techniques and practices, Plenum Press, New York, London, USA, UK.

Yamane K., Ueta A., and Shimamoto Y., 2001. Influence of physical and chemical properties of biodiesel fuels on injection, combustion and exhaust emission characteristics in a direct injection compression ignition engine. Int. J. Eng. Res., 2, 4249-4261.

Zhmud B., 2014. Viscosity blending equations. Lube-Tech - The European Lubricants Industry Magazine, 98, 1-4.

Žák M. and Marek V., 2016. Determination of ethanol concentration in biofuel by electrical properties measurement (in Czech). Listy cukrovarnické a řepařské, 132(9-10), 312-316 